\title{
Inspiratory Carbon Monoxide and Compound A Concentrations During Desflurane and Sevoflurane Anesthesia in Humans: An Observational Study
}

\author{
Christiaan Keijzer ${ }^{*}, 1$, Roberto S.G.M. Perez ${ }^{2}$ and Jaap J. De Lange ${ }^{2}$ \\ ${ }^{I}$ Department of anesthesiology and intensive care, The Netherlands Cancer Institute - Antoni van Leeuwenhoek \\ Hospital, Amsterdam, The Netherlands \\ ${ }^{2}$ Department of anesthesiology, VU University medical center, Amsterdam, The Netherlands
}

\begin{abstract}
All modern vapor anesthetics are capable of carbon monoxide $(\mathrm{CO})$ production as a result of interaction with desiccated strong base containing carbon dioxide absorbents. In desiccated absorbents, desflurane produces the highest concentrations of $\mathrm{CO}$. Sevoflurane is known to produce the nephrotoxic compound A (CA) independently from water content of the carbon dioxide absorbent. The purpose of this study was to register the average CO concentrations in forty patients receiving anesthesia with desflurane or sevoflurane after implementation of a safety protocol adapted from Woehlck et al.. This protocol was developed to prevent desiccation of the strong base containing absorbent Drägersorb 800 Plus ${ }^{\circledR}$. Methods: In 40 patients a low-flow anesthesia was maintained using an oxygen/air mixture with either sevoflurane or desflurane in combination with the $\mathrm{CO}_{2}$ absorbent Drägersorb 800 plus ${ }^{\circledR}$. CO and CA production was measured in the inspiratory limb of the anesthesia machine using a portable gas chromatograph, with a sampling frequency of 12 samples per hour. Results: No carbon monoxide was measured in any of the desflurane or sevoflurane anesthesia's. The mean concentration of CA for anesthesia with sevoflurane was $17.1 \pm 5.5$ parts per million. Conclusion: With the introduction of a safety protocol no carbon monoxide was measured in anesthesia performed with desflurane or sevoflurane. Compound $\mathrm{A}$ is almost continuously detected in anesthetic procedures with the use of sevoflurane in very low concentrations. Implementation of a simple safety protocol possibly prevents desiccation of the absorbent and could subsequently reduce the risk of carbon monoxide intoxication.
\end{abstract}

\section{INTRODUCTION}

All modern volatile anesthetic agents are known to be capable of carbon monoxide $(\mathrm{CO})$ production as a result of their interaction with desiccated carbon dioxide absorbents containing strong bases $[1,2]$. Besides $\mathrm{CO}$ production, sevoflurane also produces other degradation products $[3,4]$, the most important being fluoromethyl-2,2-difluoro-1(trifluoromethyl)vinyl ether (Compound A). Compound A has proven to be nephrotoxic in rats $[5,6]$. For CO production to occur, the water content of the strong base containing carbon dioxide absorbent sodalime needs to be less than $4,8 \%$ [1]. Compound A (CA) is also generated in combination with normally hydrated carbon dioxide absorbents [7]. In a previous laboratory study, we recorded very high concentrations of $\mathrm{CO}$ when using $3,0 \mathrm{vol} \%$ desflurane concomitantly to a desiccated strong base containing absorbent Drägersorb 800 plus $^{\circledR}$. In that study [8], other volatile anesthetic agents produced $\mathrm{CO}$ at concentrations that were the lowest for sevoflurane, and that were increasing for halothane, isoflurane and enflurane, respectively. In another study, we published the maximum concentrations of CA for sevoflurane in combination with seven different types of absorbents in fresh and desiccated condition [9]. That laboratory study evidenced only low concentrations of CA.

*Address correspondence to this author at the Department of anesthesiology and intensive care, The Netherlands Cancer Institute - Antoni van Leeuwenhoek Hospital, Amsterdam, The Netherlands; E-mail: c.keijzer@nki.nl
Because of the theoretic possibility of production of high concentrations of $\mathrm{CO}$ from desflurane when used in combination with desiccated strong base containing absorbent Drägersorb 800 plus $^{\circledR}$ we implemented a safety protocol as described by Woehlck et al. [10], when desflurane was introduced in our institution. We adapted this protocol to prevent desiccation of the carbon dioxide absorbents, while still maintain the possibility of flushing the ventilating circuits of the anesthesia machines with a flow of air. Where Woehlck's protocol used a ten minute flow of oxygen to dry expiratory limb flowmeters, our protocol used an one hour flow of air for flushing the ventilating circuits. Because of the small fraction of carbon dioxide in air this will generate water inside the absorbent, therefore preventing desiccation from the flow of air. All interventions of this protocol are described in Table 1.

Table 1. Description of Interventions to Prevent Carbon Dioxide Absorbent Desiccation

1. Anesthesia nurses were instructed to close the oxygen flow of the anesthesia machine after the operating program was finished

2. An air flow could be used to flush the ventilating circuits of the anesthesia machine, limited in duration up to one hour.

3. When at the start of the day a fresh gas flow of oxygen was detected, the absorbent was changed immediately. 
In order to gain insight in regular clinical practice after implementing this safety protocol, we wanted to compare a potentially strong $\mathrm{CO}$ producing volatile anesthetic agent (desflurane) with a weak one (sevoflurane), and simultaneously investigate if the average CA concentrations in anesthetic procedures using sevoflurane were comparable to the low ranges found in our laboratory study. Therefore, the aim of this observational study was to register the average $\mathrm{CO}$ and CA concentrations in a group of patients receiving anesthesia with desflurane or sevoflurane.

\section{METHODS}

This study was approved by the Committee on Human Research of the VU University Medical Center, where this study was performed. The study group included 40 nonsmoking patients categorized as American Society of Anesthesiologists physical status class 1 to 3 , who were scheduled for a surgical procedure that would last at least ninety minutes. Patients younger than 18 years of age or suffering from terminal renal failure were excluded. All patients of one scheduled surgery program day, were randomly assigned with randomization envelopes, to receive anesthesia with either desflurane or sevoflurane. Forty patients scheduled for 21 surgery program days were included. The anesthesia machine was a Dräger Cicero EM $^{\circledR}$ circle system. A standard bacterial humid filter was used. Patients were not premedicated with a benzodiazepine, but received only $1000 \mathrm{mg}$ paracetamol one hour before anesthesia was induced. After administration of $100 \%$ oxygen for several minutes, anesthesia was induced by $3 \mu \mathrm{g} / \mathrm{kg}$ fentanyl, 1.5 to $2.5 \mathrm{mg} / \mathrm{kg}$ propofol and $0.6 \mathrm{mg} / \mathrm{kg}$ rocuronium. Following tracheal intubation, the fresh gas flow rate (FGF) was set to $51 / \mathrm{min}$ and either desflurane or sevoflurane was introduced by a standard vaporizer. When a concentration of $4.0 \mathrm{vol} \%$ desflurane or $2.0 \mathrm{vol} \%$ sevoflurane was reached, the FGF was reduced at the discretion of the anesthesiologist to a minimum of 500 and a maximum of $1000 \mathrm{ml} / \mathrm{min}$. The ratio of the oxygen to air flow rates was adjusted to maintain the oxygen concentration in the inspiratory limb above $30 \%$. The anesthetic concentration was adjusted to maintain systolic blood pressure within $20 \%( \pm)$ of baseline. If necessary, extra fentanyl was administered. The lungs were ventilated mechanically with a tidal volume of $8 \mathrm{ml} / \mathrm{kg}$, with the ventilatory rate adjusted to maintain an end-tidal carbon dioxide concentration of $30-40 \mathrm{mmHg}$.

\section{Compound $A$ and Carbon Monoxide Measurements}

During anesthesia, gas was automatically sampled every 5 minutes from the inspiratory limb of the anesthetic circuit at a rate of $100 \mathrm{ml} / \mathrm{min}$ during 10 seconds for measuring the concentrations of compound $\mathrm{A}$ and carbon monoxide with a portable gas chromatograph (Varian Chrompack CP 2003P). The gas chromatograph (GC) was equipped with a high sensitivity thermal conductivity detector (TCD) and a Poraplot Q column for isolating CA and a Mollsieve 5A column for isolating $\mathrm{CO}$. The reliability range of detection of this setup is $1 \mathrm{ppm}$ to $1 * 10^{6} \mathrm{ppm}$ with a margin of error of $10 \%$. The GC was calibrated with a calibration mixture of 12 parts per million (ppm) CA in nitrogen (Scott specialty gasses, The Netherlands) derived from three millilitres of $99,6 \%$ pure CA (Baxter Pharmaceutical Products Inc., New Providence,
$\mathrm{NJ})$. Calibration for $\mathrm{CO}$ was performed using a mixture of $210 \mathrm{ppm} \mathrm{CO}$ in nitrogen (Hoekloos specialty gasses, Dieren), and a second mixture of $981 \mathrm{ppm} \mathrm{CO}$ in nitrogen to confirm the linearity of the TCD. The gas chromatograph (GC) was connected to a desktop PC for control of the GC and data recording, analysis and storage.

\section{Analysis of Data}

Analyzes were performed with SPSS for Windows version 12.0. Measured values are expressed as means \pm standard deviation. For comparison between samples before and after FGF reduction, the Mann-Whitney-U test was used with a significance level set at $5 \%$.

\section{RESULTS}

Demographic data of both groups are reported in Table $\mathbf{2}$.

For both groups, no $\mathrm{CO}$ was measured in any of the experiments. CA was only detected in the sevoflurane group.

Table 2. Number of Patients, Distribution of Sex, Mean Age and Anesthesia Duration

\begin{tabular}{|c|c|c|}
\hline & Desflurane & Sevoflurane \\
\hline \hline Number of patients & 20 & 20 \\
\hline Male/female & $9 / 11$ & $8 / 12$ \\
\hline Age (yr) & $60.2 \pm 15.2$ & $54.6 \pm 18.1$ \\
\hline Duration & $2 \mathrm{~h} 21 \mathrm{~m} \pm 28 \mathrm{~m}$ & $2 \mathrm{~h} 18 \mathrm{~m} \pm 30 \mathrm{~m}$ \\
\hline
\end{tabular}

Legend: yr=years, $h=$ hours, $m=$ minutes. Values for age and duration of anesthesia are mean $\pm \mathrm{SD}$

The mean concentration of CA for all patients receiving sevoflurane anesthesia was 17.1 parts per million ( $\mathrm{ppm}$ ) with a standard deviation of $5.5 \mathrm{ppm}$. The minimum concentration of CA was $0.0 \mathrm{ppm}$ and the maximum concentration 37.5 $\mathrm{ppm}$. Although CA was detected in most of the inspiratory limb of patients at the start of the experiment, four had a minimum CA concentration of $0.0 \mathrm{ppm}$ at that time. For all anesthetic procedures using sevoflurane, an significant increase in CA concentration was measured (Mann-Whitney-U $\mathrm{p}=0.01$ ) during the 5 to 10 minutes following the FGF reduction. Subsequently, the CA concentration seemed to stabilize around the maximum value for the experiment. The mean CA concentration, as well as the minimum and maximum observed concentrations, is displayed for all anesthetic procedures with sevoflurane in Table $\mathbf{3}$.

The time course of change of measured mean CA concentrations for every five minute sample is depicted in Fig. (1).

\section{DISCUSSION}

This study demonstrates that, during controlled clinical situations, desflurane and sevoflurane anesthesia is not associated with carbon monoxide production, and that sevoflurane anesthesia is associated with only small amounts of Compound A generation. In the desflurane group, we did not measure any $\mathrm{CO}$ in the inspiratory limb, although we would have expected at least a few ppm from the patients metabolism [11]. Possibly, these small concentrations of CO did 
Table 3. Compound A Concentrations

\begin{tabular}{|c|c|c|c|}
\hline Anesthesia nr. & Mean $[\mathrm{CA}]$ & Minimum [CA] & Maximum [CA] \\
\hline 1 & $16.3 \pm 4.4$ & 1.5 & 23.1 \\
\hline 2 & $20.9 \pm 6.7$ & 0.0 & 27.4 \\
\hline 3 & $18.0 \pm 0.7$ & 16.3 & 20.0 \\
\hline 4 & $14.0 \pm 4.9$ & 0.0 & 17.9 \\
\hline 5 & $13.6 \pm 3.1$ & 4.7 & 17.1 \\
\hline 6 & $14.8 \pm 3.1$ & 1.1 & 19.6 \\
\hline 7 & $15.9 \pm 2.2$ & 12.9 & 19.0 \\
\hline 8 & $18.4 \pm 3.2$ & 9.0 & 23.9 \\
\hline 9 & $18.2 \pm 3.9$ & 0.0 & 22.1 \\
\hline 10 & $16.1 \pm 3.0$ & 7.8 & 20.0 \\
\hline 11 & $21.2 \pm 5.3$ & 8.3 & 29.7 \\
\hline 12 & $21.3 \pm 3.0$ & 17.4 & 30.3 \\
\hline 13 & $15.1 \pm 3.6$ & 0.3 & 20.7 \\
\hline 14 & $13.4 \pm 1.9$ & 9.8 & 15.8 \\
\hline 15 & $14.7 \pm 0.6$ & 13.0 & 15.3 \\
\hline 16 & $28.8 \pm 7.3$ & 0.0 & 37.5 \\
\hline 17 & $10.9 \pm 1.4$ & 6.2 & 14.6 \\
\hline 18 & $13.7 \pm 2.7$ & 5.1 & 16.2 \\
\hline 19 & $17.0 \pm 5.3$ & 3.7 & 22.8 \\
\hline 20 & $17.9 \pm 5.3$ & 4.6 & 23.6 \\
\hline \multicolumn{4}{|c|}{$\begin{array}{l}\text { Legend: Mean, minimum and maximum compound A (CA) concentrations from al } \\
\text { anesthetic procedures using sevoflurane. Column } 1 \text { states the anesthesia number, col } \\
\text { umn } 2 \text { the mean CA concentration } \pm \text { SD for that experiment. Column } 3 \text { and } 4 \text { display } \\
\text { respectively the minimum and maximum CA concentration. Concentrations in parts per } \\
\text { million (ppm). }\end{array}$} \\
\hline
\end{tabular}

not reach the inspiratory limb because of the small spill of gas in the semi-closed anesthesia system we used. The fact that no $\mathrm{CO}$ was produced in these anesthetic procedures means that the water content of the absorbent was always above $4,8 \%$ as demonstrated by Fang et al. [1]. This demonstrates the rareness of complete desiccation of the absorbent in this clinical situation. This prevention of complete desiccation is probably due to the fact that the anesthesia nurses were instructed to use the safety protocol as described in the introduction. In this protocol, a flow of air is used when flushing the ventilating circuits of the anesthesia machines after surgery is necessary. A flow of air contains $0.03 \%$ of carbon dioxide that generates water when it reacts with the calcium hydroxide inside the absorbent, therefore preventing the absorbent from desiccating. Furthermore, a fresh gas flow of oxygen was never found in the anesthesia machine at the start of each study day, and the absorber did not have to be changed at any time. A limitation of this study is that this protocol was not tested against performance of anesthetic procedures without a safety protocol (as was current practice before introduction of desflurane in our institution) while using this strong base containing absorbent in combination with desflurane. For ethical reasons this option was not considered. Because of the lack of a control group in this study we cannot conclude that the safety protocol used is responsible for prevention of desiccation of the absorbent. However, the study by Woehlck et al. [10] did have a control group and that study demonstrated the relation between the implementation of a safety protocol and reduction of patient exposure to carbon monoxide, indicating prevention of desiccation of the absorbent.

In the anesthetic procedures performed with sevoflurane, we measured an increase of the measured CA concentration after the FGF was reduced from a flow of $51 / \mathrm{min}$ to a flow of $500-1000 \mathrm{ml} / \mathrm{min}$. This is in accordance with other studies [12-15] which demonstrated that a low flow will increase the amount of CA measured inside the circle system. This

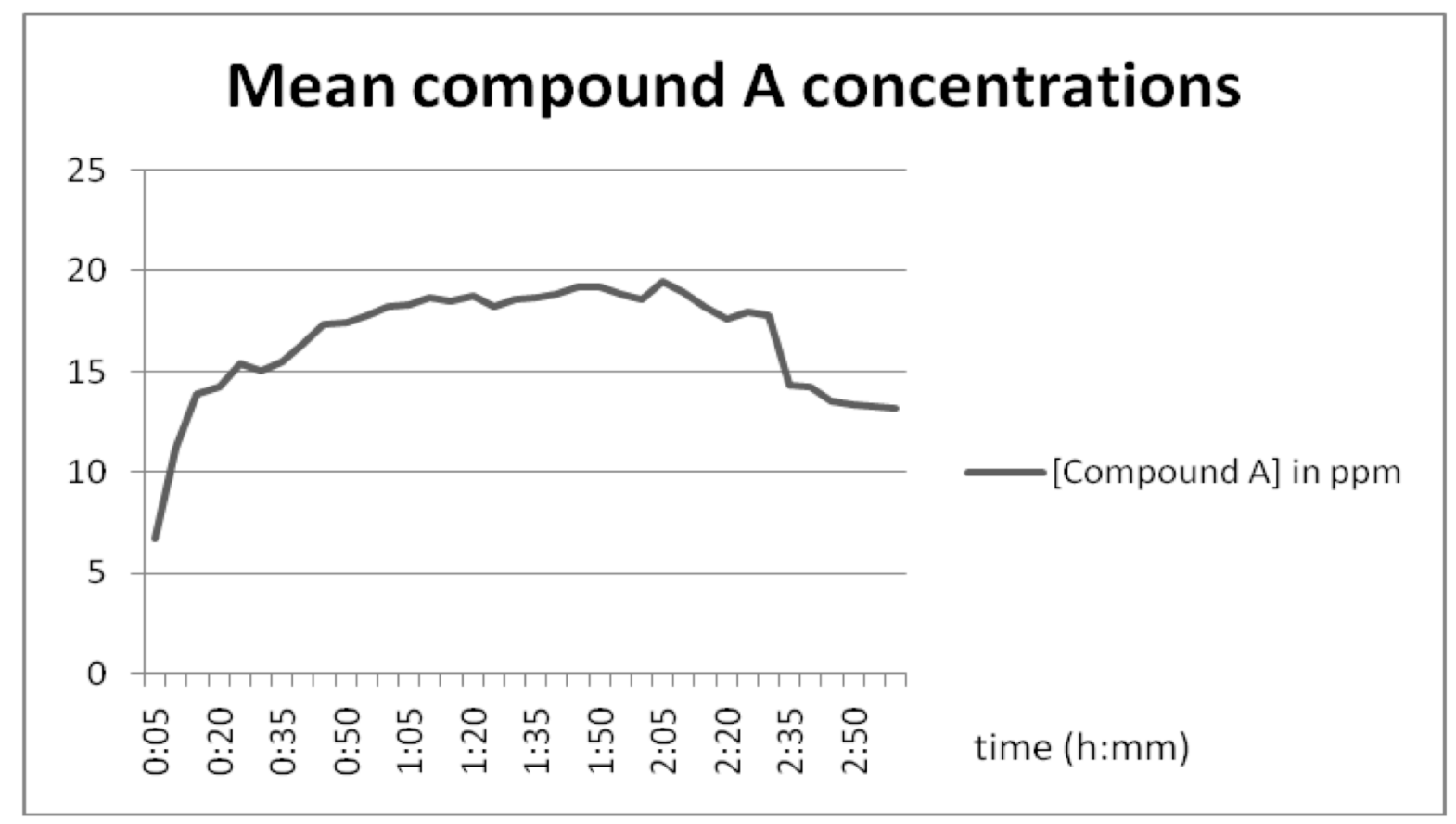

Fig. (1). Mean Compound A concentrations in parts per million ( $\mathrm{ppm}$ ) for every five minute sample. Time on the $\mathrm{x}$-axis in hour:minutes. 
variation of FGF may explain the observed large range in mean CA concentrations (between 13.4 and $28.8 \mathrm{ppm}$ ).

The CA concentrations measured in the present study are higher than in our previous laboratory study [9]. This is most probably due to the fact that we used 1.5 to $2.5 \mathrm{vol} \%$ sevoflurane in this study instead of the $0.8 \mathrm{vol} \%$ sevoflurane with $60 \%$ nitrous oxide in our laboratory study. A study by Yamakage et al. [16] described a comparable increase of CA production when exposing Drägersorb 800 plus ${ }^{\circledR}$ to 1 and $2 \%$ sevoflurane respectively. The CA concentrations found in this study are comparable with concentrations found in other studies $[12,17,18]$ using the same concentrations of sevoflurane during low-flow anesthesia. In the first samples of four anesthetic procedures using sevoflurane (three of which were the first anesthesia of the day) no CA was measured. We assume that this lack of CA production was due to flushing of the anesthesia machine with air overnight or between anesthetic procedures. For the majority of anesthetic procedures, small amounts of CA were measured in the first sample, which were probably the result of $\mathrm{CA}$ formation from the previous anesthesia.

Although transient nephrotoxicity was demonstrated by Eger et al. [19] and Goldberg et al. [20] with respectively $80-160 \mathrm{ppm} / \mathrm{h}$ and $240 \mathrm{ppm}-\mathrm{h}$ of CA exposure in humans, the majority of publications demonstrate no nephrotoxicity in humans with the use of sevoflurane in combination with any kind of absorbent [21-23]. The results of this study, together with the results from our laboratory study [9], confirm these observations. From these results we therefore conclude that sevoflurane can be safely used in low flow anesthesia in contradiction with the FDA recommendation to use a FGF of more than $2 \mathrm{~L} / \mathrm{min}$.

\section{CONCLUSION}

No carbon monoxide was measured during anesthetic procedures performed with desflurane or sevoflurane. This was possibly attributable to the use of a safety protocol, whereby the flow of air used to flush the ventilating circuits of the anesthesia machine does not desiccate the carbon dioxide absorbent. Compound A is almost continuously measured in anesthetic procedures with sevoflurane in very low concentrations in low flow anesthesia.

\section{REFERENCES}

[1] Fang ZX, Eger EI, Laster MJ, Chortkoff BS, Kandel L, Ionescu P. Carbon monoxide production from degradation of desflurane, enflurane, isoflurane, halothane, and sevoflurane by soda lime and baralyme. Anesth Analg 1995; 80: 1187-93.

[2] Stabernack CR, Brown R, Laster MJ, Dudziak R, Eger EI. Absorbents differ enormously in their capacity to produce compound A and carbon monoxide. Anesth Analg 2000; 90: 1428-35.

[3] Baum J, Sitte T, Strauss JM, Forst H, Zimmerman H, Kugler B. Absorption and degradation of sevoflurane in dry soda lime. Anästhesiol Intensivmed 1998; 39: 11-6.

[4] Brown B Jr. Sevoflurane: introduction and overview. Anesth Analg 1995; 81: S1-3.
[5] Iyer RA, Baggs RB, Anders MW. Nephrotoxicity of the glutathione and cysteine S-conjugates of the sevoflurane degradation product 2-(fluoromethoxy)-1,1,3,3, 3- pentafluoro-1-propene (Compound A) in male Fischer 344 rats. J Pharmacol Exp Ther 1997; 283: 1544-51.

[6] Kharasch ED, Thorning D, Garton K, Hankins DC, Kilty CG. Role of renal cysteine conjugate beta-lyase in the mechanism of compound A nephrotoxicity in rats. Anesthesiology 1997; 86: 160-71.

[7] Eger EI, Ionescu P, Laster MJ, Weiskopf RB. Baralyme dehydration increases and soda lime dehydration decreases the concentration of compound A resulting from sevoflurane degradation in a standard anesthetic circuit. Anesth Analg 1997; 85: 892-8.

[8] Keijzer C, Perez RS, de Lange JJ. Carbon monoxide production from five volatile anesthetics in dry sodalime in a patient model: halothane and sevoflurane do produce carbon monoxide; temperature is a poor predictor of carbon monoxide production. BMC Anesthesiol 2005; 5: 6 .

[9] Keijzer C, Perez RS, de Lange JJ. Compound A and carbon monoxide production from sevoflurane and seven different types of carbon dioxide absorbent in a patient model. Acta Anaesthesiol Scand 2007; 51: 31-7.

[10] Woehlck HJ, Dunning M III, Connolly LA. Reduction in the incidence of carbon monoxide exposures in humans undergoing general anesthesia. Anesthesiology 1997; 87: 228-34.

[11] Coburn RF. Endogenous carbon monoxide production. N Engl J Med 1970; 282: 207-9.

[12] Bito H, Ikeda K. Effect of total flow rate on the concentration of degradation products generated by reaction between sevoflurane and soda lime. Br J Anaesth 1995; 74: 667-9.

[13] Bito H, Ikeuchi Y, Ikeda K. Effects of low-flow sevoflurane anesthesia on renal function: comparison with high-flow sevoflurane anesthesia and low-flow isoflurane anesthesia. Anesthesiology 1997; 86: 1231-7.

[14] Fang ZX, Eger EI. Factors affecting the concentration of compound A resulting from the degradation of sevoflurane by soda lime and Baralyme in a standard anesthetic circuit. Anesth Analg 1995; 81: 564-8.

[15] Baxter AD. Low and minimal flow inhalational anaesthesia. Can J Anaesth 1997; 44: 643-52.

[16] Yamakage M, Yamada S, Chen X, Iwasaki S, Tsujiguchi N, Namiki A. Carbon dioxide absorbents containing potassium hydroxide produce much larger concentrations of compound A from sevoflurane in clinical practice. Anesth Analg 2000; 91: 220-4.

[17] Bito H, Ikeda K. Closed-circuit anesthesia with sevoflurane in humans. Effects on renal and hepatic function and concentrations of breakdown products with soda lime in the circuit. Anesthesiology 1994; 80: 71-6.

[18] Higuchi H, Adachi Y, Arimura S, Kanno M, Satoh T. Compound A concentrations during low-flow sevoflurane anesthesia correlate directly with the concentration of monovalent bases in carbon dioxide absorbents. Anesth Analg 2000; 91: 434-9.

[19] Eger EI, Gong D, Koblin DD, et al. Dose-related biochemical markers of renal injury after sevoflurane versus desflurane anesthesia in volunteers. Anesth Analg 1997; 85: 1154-63.

[20] Goldberg ME, Cantillo J, Gratz I, et al. Dose of compound A, not sevoflurane, determines changes in the biochemical markers of renal injury in healthy volunteers. Anesth Analg 1999; 88: 437-45.

[21] Ebert TJ, Arain SR. Renal responses to low-flow desflurane, sevoflurane, and propofol in patients. Anesthesiology 2000; 93: 1401-6.

[22] Ebert TJ, Messana LD, Uhrich TD, Staacke TS. Absence of renal and hepatic toxicity after four hours of 1.25 minimum alveolar anesthetic concentration sevoflurane anesthesia in volunteers. Anesth Analg 1998; 86: 662-7.

[23] Obata R, Bito H, Ohmura M, et al. The effects of prolonged lowflow sevoflurane anesthesia on renal and hepatic function. Anesth Analg 2000; 91: 1262-8. 